\title{
Subvertendo algumas dicotomias instituídas pelo hábito
}

\author{
Mary Jane P. Spink \\ Núcleo de Estudos e Pesquisas em Práticas Discursivas e Produção de Sentidos \\ Pontifícia Universidade Católica de São Paulo \\ mjspink@pucsp.br
}

\begin{abstract}
Resumen
Estabelecendo um diálogo com Thomas Ibañez (2001), lan Hacking (1999), Donna Haraway (1991) e a Actor Network Theory de John Law e colegas (1999), este paper busca refletir sobre a possibilidade de superação da dicotomia entre realismo e construcionismo. Partindo da pergunta "por que como psicólogos sociais, deveríamos nos posicionar nessa contenda?", explora alguns caminhos que vêm sendo trilhados no debate contemporâneo sobre as bases do conhecimento. Argumentando que deveríamos abandonar essa e todas as demais dicotomias que vêm no arrastão do realismo, adota a postura que vivemos em um mundo híbrido que é uma mescla de percepções culturais, ordens morais locais, estratégias de governamentalidade, objetos e tecnologias: ou seja, em uma rede de materialidades que inclui nossos modos de falar sobre o mundo. Tendo em vista que essa postura implode também a dicotomia fato/ficção, busca, ainda, refletir sobre as implicações para a pesquisa e para a definição do que conta como conhecimento legítimo, assumindo a posição de que os relatos da ciência são também eles gêneros de narrativas.
\end{abstract}

Palabras clave: construcionismo; práticas discursivas; materialidades

Por que deveríamos nos posicionar como realistas ou construcionista? Por que, como psicólogos e psicólogas sociais, teríamos que entrar nessa complicada arena do debate ontológico para poder falar de nossa postura epistemológica? Quem, no diálogo estabelecido com a psicologia social nessa pós-modernidade aí se posiciona? E com que autoridade?

Tomás Ibañez (2001) certamente o faz. E para dar lastro à sua postura anti-realista estabelece um diálogo com a física quântica. Certamente nos convence, nesse diálogo, que a matéria oscila em sua interação com o humano. ${ }^{1}$ Mas ao assim fazer, Ibañez abre o flanco para a desconfiança que alimenta gente como Sokal (data): entendemos de fato a formulação quântica? Eu certamente não tenho formação que me permita entender os conceitos da física! Precisamos dela? Por que escolher como interlocutor (ou seriam muletas?) a física quântica visto que, se lan Hacking estiver correto, esta

\footnotetext{
${ }^{1}$ Mas também os teóricos da Actor Network Theory (ANT) falam disso e tratam do fenômeno a partir do conceito de relational materiality sendo que para tal não precisam recorrer a artifícios extrateóricos.
} 
perdeu seu status - se medirmos em termos de apoio financeiro - diante da mais instrumental física dos estados sólidos (para não falar da biologia molecular)?

Hacking (2001) faz outro tipo de alerta, invocando os milenares debates da própria filosofia. Posicionando-se, como Ibáñez, como não conciliatório, ${ }^{2}$ nos fala de três arenas de discórdia: contingência, nominalismo e estabilidades. Contingência refere-se aos processos históricos que sustentam a emergência de um determinado conceito ou idéia. Por exemplo, a afirmação que a idéia de quark não foi inevitável; emergiu ao largo do processo histórico sendo que outra física imaginária, fundamental e igualmente bem sucedida poderia ter emergido. Em suma, contingência significa não determinação sem entretanto sujeitar a emergência da teoria à experiência, sendo por ela infradeterminada.

Já o nominalismo traz ressonâncias de temas filosóficos tradicionais. Trata-se de uma postura substantivista que, em sua versão mais extrema sustenta que os itens agrupados sob um substantivo comum nada têm de particular além de serem denominados por uma mesma palavra. Hacking ilustra o 'espírito da discórdia' usando a seguinte formulação:

"Um bando tem a esperança que o mundo, por sua própria natureza, pode estar estruturado da forma em que o descrevemos. Até mesmo quando não tivermos captado as coisas corretamente; é pelo menos possível que o mundo esteja estruturado assim. A única coisa que importa na investigação é descobrir o mundo. Os fatos estão ali, dispostos tal como são, não importa como os descrevemos. Pensar de outro modo é não ter respeito para com o universo; é pecar por soberba; exaltar a pequenez do pensamento humano.

$O$ outro bando diz que sente um respeito ainda mais profundo pelo mundo. $O$ mundo é tão autônomo, tão sí-mesmo, que nem ao menos tem em si o que chamamos de estrutura. Nós fabricamos nossas frágeis representações sobre esse mundo, mas toda estrutura que lhe podemos atribuir está apenas em nossas representações. Evidentemente estas estão sujeitas a severas restrições. Temos expectativas sobre nossas interações com o mundo material e quando não se cumprem, não mentimos sobre ele, nem a nós mesmos, nem aos demais. No domínio imparcialmente público da ciência, os aparelhos engenhosos e a genialidade das teorias servem para que sigamos sendo eqüitativamente honestos". (2001:142)

Quanto às explicações da estabilidade - o terceiro ponto conflitante discutido por Hacking - estas nos fazem adentrar no terreno do que se poderia chamar de 'progresso da ciência'. Se a questão focal das reflexões de Thomas Kuhn era compreender a revolução, o problema hoje, segundo Hacking, é entender a estabilidade das leis da natureza. Retoma-se assim a contraposição entre a postura de Leibniz e Locke. Na postura racionalista de Leibniz, as razões que subjazem às verdades são internas a essas verdades. Na postura empiricista de Locke, as verdades sobre o mundo são sempre externas e estão ancoradas em nossas experiências. Assim,

\footnotetext{
${ }^{2}$ Hacking (2001:117) propõe que há duas estratégias possíveis diante do debate ontológico: conciliatória (algo pode ser real e ser uma construção (posição que o autor defende no capítulo 5 de seu livro) e não conciliadora (posição que assume no capítulo intitulado Que pasa com las ciencias naturales?)
} 
"Os construcionistas mantêm que as explicações da estabilidade das crenças científicas envolvem, pelo menos em parte, elementos que são externos ao conteúdo manifesto da ciência. Estes elementos incluem habitualmente fatores sociais, interesses, redes ou seja como forem descritos. Os oponentes mantêm que, seja qual for o contexto da descoberta, a explicação da estabilidade é interna à própria ciência." (2001:155)

Eu certamente não tenho a formação filosófica que me permita versar sobre esses temas com confiança. Retomo assim a pergunta: precisamos mesmo formular nossas inquietações contrapondo realismo e construcionismo? Não seria melhor se abandonássemos por ora esta e todas as dicotomias que nos aprisionam, abrindo mão da discussão sobre o estatuto do real e de todas as demais dicotomias que vem no arrastão do realismo?

Talvez seja isso que Dona Haraway fez. Seu alvo não é o debate quiçá estéril da filosofia; sua plataforma é política e volta-se à invenção de novas formas de subjetividades que possibilitariam novas posições de sujeito que superem as discriminações baseadas em gênero, raça etc. Seu alvo são certas dicotomias ontogênicas que são desfeitas mediante pelo menos três rupturas: animal/humano; organismos/máquinas e físico/não físico (physical/non-physical). Desfaz-se, assim, sem nem mesmo falar sobre realidade, algumas das bases que milenarmente sustentam nossa visão antropocêntrica de realidade. O faz sem dizer que é isso que está fazendo; ou seja, não vê como necessário posicionar-se como realista ou construcionista em qualquer que seja a modalidade desses "ismos".

Também outros subvertem essa dicotomia adotando o caminho da oscilação: ora vêem como necessário tratar o mundo de fatos e artefatos como real; ora os tratam como construções sociais. É o caso da discussão que Ulrich Beck faz sobre riscos

"Apenas ao pensar riscos em termos de realidade, ou melhor, de poder vir a tornarse real (uma virtualidade) é que sua materialização pode ser entendida. Mas é apenas pensando-os como construções que podemos entender sua 'essência' indefinidamente protelada." (2000:213)

Para Beck os riscos são concomitantemente reais e constituídos pela percepção e construção social. Sua realidade deriva dos impactos que estão enraizados na produção industrial e na pesquisa científica. Mas o conhecimento que temos dos riscos está assentado na história e símbolos de nossa cultura: a percepção é sempre e necessariamente contextual e local (p.219). E para entender este paradoxo Beck, também ele, considera que temos que abrir mão do enquadre dicotômico que formatou nossas sensibilidades modernas: na sociedade de risco, por exemplo, perdeu-se a distinção clara entre natureza e cultura. Vivemos, como propõe Latour, em um mundo híbrido que é uma conjugação de percepções culturais, julgamentos morais, políticas, tecnologias que vem sendo construídos historicamente em redes de agenciamentos e se tornaram dados duros pelo efeito de serem encerrados em caixas pretas que nos fazem esquecer suas origens tão humanas.

Não se trata de aderir aos discursos "pós" (pós-moderno, por exemplo). Trata-se de reconhecer que os riscos, por exemplo, são híbridos feitos pela mão humana:

"Eles incluem e combinam políticas, éticas, matemáticas, comunicação de massa, definições culturais, percepção e, mais importante, não é possível separar esses aspectos e as 'realidades' se quisermos entender a dinâmica política e cultural do mundo na sociedade de risco. Portanto, risco não é apenas uma noção usada de 
forma central em várias disciplinas, é também a maneira como a 'sociedade híbrida' observa, descreve, valoriza e critica sua própria hibricidade." (2000:221)

É inegável, aqui, a influência de Bruno Latour em sua fase ANT - ou seja como um dos importantes colaboradores da Actor Network Theory. Nós, pessoas que habitamos o mundo que criamos com nossas experiências e artefatos, somos, como é o mundo que criamos, criaturas tipo ODO, personagem da série Star Trek: seres e coisas capazes de sermos multiformes e polissêmicos. De sermos nós em complexas redes, entendidas não mais como estruturas e posições, mas como movimentos: "Tanto sujeitos como os objetos são descentrados", nos diz Annie Dugdale (1999). O que está em pauta é a conectividade de diferentes tipos de dispositivos, inscrições, formas e fórmulas em locais muito locais, muito práticos e muito pequenos (Latour, 1999:17). Uma exploração das estruturas do social vistas "de perto", de muito perto. Onde agenciamentos de humanos e não humanos são essencialmente descentrados.

Claro, mantém-se aí a dicotomia que Haraway já desfez: organismos e máquinas. Mantém-se? Ou na imbricação proposta pela noção de materialidades relacionais (relationship materialities) já não se distingue mais o status ontológico de pessoas e materialidades que as constituem enquanto tal? Segundo John Law e Annemarie Moll (1995) materialidades e socialidades são produzidas conjuntamente: "Quando olhamos para o social estamos também olhando para a produção de materialidades. E quando olhamos para os materiais, estamos testemunhando a produção do social (1995: ).

É essa a base da noção de materialidade relacional: "materiais são constituídos interativamente. Fora de suas interações eles não têm existência; não tem realidade. Máquinas, pessoas, o mundo natural, o divino - são todos efeitos ou produtos" (Law \& Moll, 1995: ). E também as pessoas são efeitos relacionais. Eles podem ou não ser atores na rede de interações e os atores nesta rede podem ser também não humanos.

A atenção é assim fixada nas conexões parciais: os materiais, as socialidades e as histórias que contamos sobre eles são como retalhos costurados em uma colcha; como há muitas linhas possíveis e muitas tramas, a atenção se desloca para os modos locais de costura.

Bruno Latour, na história contada por Law e Moll para ilustrar a característica fractal ${ }^{3}$ da rede, descreve como Louis Pasteur criou uma rede de fragmentos e pedaços no processo de desenvolvimento, teste e legitimação da imunização do gado contra o Antrax. Bactéria, culturas, microscópios, laboratórios, assistentes de laboratório, fazendas e fazendeiros, vacas, doenças, vacinas - tudo isso e muito mais fizeram parte da montagem. Então, a história de Pasteur nos conta sobre o empreendimento científico. Mas também nos fala sobre Pasteur ele mesmo. Então quem era ele? Bem isso é complicado, diz Latour, e há muitas respostas. Ele foi um corpo físico, um organismo, um cidadão francês, um cientista que era também político, um cientista de laboratório, um membro de família, um político falido. Depende onde ou como olhamos. Esse é então o sentido desta história. Pasteur o cientista de sucesso é uma rede organizada; um efeito relacional. E também, sob outras circunstâncias, um ponto nesta rede (Law \& Moll, 1995)

Nesta história, cada uma destas posições é fixada temporariamente pelas materialidades que se fazem presentes: o Pasteur cientista usa jaleco branco e manipula instrumentos, vidros, pipetas e

${ }^{3}$ Um fractal é uma linha que ocupa mais de uma dimensão mas menos do que duas (Law, 1999:12) 
anotações e tudo o mais que faz parte de um laboratório de pesquisa, incluindo os demais membros da equipe e os animais usados nos experimentos.

Cada um desses objetos é também um nó em uma rede de oscilações. Por exemplo, tenho alguns belos vidros de farmácias vitorianas que ganhei de um colega quando trabalhava em uma instituição que havia sido hospital de isolamento para as febres que assolavam a Inglaterra da revolução industrial. Uso as garrafas de água quente como suporte de livros; uso o inalador como enfeite; uso os vidros de farmácia como vasos para colocar flores.

Cabe aqui introduzir a noção de performatividade: nesse enquadre, que já não mais se encaixa confortavelmente na dicotomia entre realidade e construção, as entidades, humanas e não humanas adquirem sua forma como conseqüência das relações nas quais estão localizadas. Conseqüentemente, tais entidades são performadas nas e por meio dessas relações. $E$ eis aqui um paradoxo: de um lado a noção de performatividade tem como conseqüência que tudo é incerto e reversível. De outro, a performatividade gera durabilidade e fixidez. Voltamos assim ao paradoxo do risco na acepção de Beck!

Annemarie Moll (1999) nos fala sobre Política Ontológica; ou seja sobre a maneira como o "real" está implicado no plano político e vice versa. A ontologia, no discurso filosófico, define o que é da ordem do real; define as condições de possibilidade com as quais vivemos. Ao associar o termo ontologia com política ela está sugerindo que não há tais condições de possibilidade. Esta enfatizando que a realidade não precede nossas práticas cotidianas mas é formatada no interior de tais práticas. Assim, ela utiliza o termo "política" para enfatizar que o caráter da realidade é aberto e sujeito a contestações. Essa desconstrução da divisão entre realidade e o fazer humano vem sendo feita em instâncias diversas. Mas há diferenças. Moll fala de duas tendências recentes que rompem com o realismo mas se distanciam da proposta do Actor-Network Theory: o perspectivismo e o construcionismo. O perspectivismo rompeu com a idéia de uma verdade única; multiplicou os olhares e fez grassar o pluralismo. Mas não multiplicou a realidade que, no centro de tantos olhares distintos, permanece singular, intangível, intocável (1999:76).

O construcionismo também traz consigo a idéia de pluralidade: é possível pensar em construções alternativas da realidade, admissível num momento passado mas que se esvaeceram diante de certas forças e processos sociais. A pluralidade, no caso, é jogada para o passado, para um devir que não se cristalizou. Como diz Hacking: o X (um fenômeno qualquer) não precisaria ser desta forma. Mas cristalizou-se como essência.

Já no enquadre da ontologia como política não se trata de pluralismos presentes ou potenciais. Tratase de trabalhar ontologia no plural: como múltiplas ontologias, pois se a realidade é performada; se é historicamente e culturalmente localizada, então é também múltipla. Não estamos mais falando de perspectivas ou construções, mas de intervenção e performance. Para Moll, intervenção e performance sugerem que a realidade é feita (done) e en-acionada (enacted) ao invés de ser observada. Ao invés de ser vista por uma multiplicidade de olhos enquanto mantém-se intocada no centro, a realidade é manipulada por meio de instrumentos variados no curso de uma diversidade de práticas.

"Nas histórias sobre performance massa corporal (fleshiness), opacidade e peso não são atributos de um único objeto com uma essência que se esconde. E nem é o papel dos instrumentos desnuda-los como se fossem muitos aspectos de uma única realidade. Ao invés de serem atributos ou aspectos, eles são versões distintas do objeto, versões que os instrumentos ajudam a en-acionar (enact). São objetos 
distintos e ao mesmo tempo relacionados. São múltiplas formas da realidade." (p.77)

\section{Concluindo}

Obviamente, neste curto espaço de tempo não é possível aprofundar esse instigante debate que busca descentrar o humano das nossas maneiras de compreender o mundo. Não é tarefa pequena e só nos resta o consolo de que nós, ocidentais, já fomos partícipes de um esforço de descentramento que levou da revelação divina ao cogito cartesiano. Ficam muitas questões pendentes e listo algumas:

1. Qual o estatuto da linguagem quando levamos em conta os aspectos não lingüísticos das materialidades e socialidades?

2. Em que medida a atenção ao nível local - à performatividade e circulação entre os nós da rede - permite também recuperar as dimensões históricas dessas materialidades e socialidades: as permanências de certos repertórios que usamos hoje de forma polissêmica.

3. Se o real - os humanos e não humanos que o compõe - oscila de acordo com o nó da rede que Ihes dá agenciamento, qual o estatuto de meus dados de pesquisa? Se a noção de agenciamento é fluida e contextual, porque damos estatuto especial para a fala de um sujeito que, para fins de maior rigor, gravamos, transcrevemos e tomamos o cuidado de interpretar "em contexto", mantendo, por exemplo, a relação da parte com o todo do diálogo travado (Spink e Lima, 1999)?

4. Em suma, quais são as implicações metodológicas de assumirmos plenamente a proposta que há múltiplas histórias a serem contatas e estas nos falam de realidades múltiplas?

\section{Referências Bibliográficas}

Beck, U. (2000). Risk society revisited: theory, politics and research programmes. Em, B. Adam; U. Beck \& J. van Loon (Eds), The Risk Society and Beyond. Sage, p. 211-229.

Dugdale, A. (1999): Materiality: juggling sameness and difference. Em, J. Law \& J. Hassard (Eds), Actor Network Theory and After. Oxford, UK.: Blackwell, p. 113-135.

Hacking , I. (2001). ?Que pasa con las ciencias naturals. In, I. Hacking, la Construcción Social de Qué?. Barcelona, ES: Paidos Ibérica, p. 109-169.

Ibañez, T. (2001). La realidad no existe: algunas consideraciones epistemológicas y ontológicas a partir de la extraña realidad cuántica. Em. T. Ibáñez, Municiones para Disidentes. Barcelona, ES: Gedisa, p. 17-52.

Haraway, D. (1991). A cyborg manisfesto: science, technology and socialist-feminism in the late twentieth century. Em, D. Haraway, Simians, Cyborgs and Women: The Reinvention of Nature. New York: Routledge, p. 149-181.

Latour, B. (1999). On recalling ANT. Em, Em, J. Law \& J. Hassard (Eds), Actor Network Theory and After. Oxford, UK.: Blackwell, p. 16-25. 
Law, J. e Moll, A. (1995). Notes on materiality and sociality. The Sociological Review 43(2): 274-294.

Moll, A. (1999). Ontological politics. A word and some questions. Em, Em, J. Law \& J. Hassard (Eds), Actor Network Theory and After. Oxford, UK.: Blackwell, p. 74-89.

Spink M.J. e Lima, H. (1999). Rigor e visibilidade: a explicitação dos passos da interpretação. Em, M.J.Spink (Org.), Práticas Discursivas e Produção de Sentidos no Cotidiano: Aproximações Teóricas e Metodológicas. São Paulo: Cortez, p.93-122

\section{Referencia}

Spink, M.J. (2003). Subvertendo algumas dicotomias instituídas pelo hábito. Athenea Digital, 4. Referencia. Disponible en http://antalya.uab.es/athenea/num4/spink.pdf 